\title{
Patterns of local-regional recurrence after conformal and intensity-modulated radiotherapy for head and neck cancer
}

\author{
Safora Johansen ${ }^{1,2^{*}}$, Mathilde H. Norman', Einar Dale1, Cecilie D. Amdal', Torbjørn Furre', Eirik Malinen ${ }^{3,4}$
} and Jan F. Evensen ${ }^{1}$

\begin{abstract}
Aim: To evaluate the patterns of loco-regional recurrences in head and neck cancer patients

Methods: Twenty-six out of 112 patients treated with primary or postoperative 3D CRT or IMRT for their primary and recurrent disease between 2007 and 2013 were included. The CT images of recurrent disease were rigidly registered with the primary $C T$ images for each patient. To assess overlaps and overlap localization, the recurrence volume overlapping with the primary target volume was identified. For relapses occurring in the regional lymph nodes, the epicenter distance in recurrences and primary volumes and dose in recurrences were also identified. The recurrences were defined as in-field, marginal or out-of-field.

Results: The majority of the failures occurred within 1 year after completed primary treatment. The dose differences in recurrence volume were not statistically significant when patients were treated with IMRT or 3D CRT. Recurrence in $15 / 26$ of the included patients occurred in the regional lymph nodes located fully or partly inside the primary target volume or the elective lymph node region. The majority of recurrences were recognized as in-field, independent of the primary treatment.

Conclusion: Recurrence in the majority of the patients occurred in the regional lymph nodes located in high dose area. The cause of recurrence may be due to inadequate total dose in the primary treatment and/or lack of optimal primary diagnosis leading to inadequate primary target delineation.
\end{abstract}

Keywords: Head and neck cancer, Radiotherapy, Radiotherapy technique, Regional lymph node, Recurrence, Relapse

\section{Introduction}

The incidence of oral cavity/pharynx and larynx cancer in Europe was estimated to 100,000 and 40,000, respectively, in 2012 [1]. In Norway, 800 patients were diagnosed with head and neck cancer (HNC) in 2014, representing $2.5 \%$ of the total incidence of malignant disease [2].

Management of HNC is multi-disciplinary; surgery, radiotherapy (RT) with or without concomitant

\footnotetext{
* Correspondence: Safora.johansen@hioa.no

'Department of oncology, Division of cancer Medicine, Surgery and

Transplantation (KKT), Oslo University Hospital-Radium hospital, Montebello, 0310 Oslo, Norway

${ }^{2}$ Oslo and Akershus University College of Applied Sciences, Faculty of Health

Sciences, Oslo, Norway

Full list of author information is available at the end of the article
}

chemotherapy. High dose RT (prescribing doses typically of $70 \mathrm{~Gy}$ ) is necessary to achieve cure, but may result in side effects. The employment of three-dimensional conformal radiotherapy (3D CRT) and intensity-modulated radiotherapy (IMRT) have permitted treatment largely conforming to the disease extensions for the individual patient [3-6]. However, each year, $30-50 \%$ of patients with locally advanced $\mathrm{HNC}$, experience loco-regional relapse [7]. Loco-regional recurrence is still one of the major causes of failure in HNC after radical treatment [7]. Therefore, it is important to evaluate the patterns of loco-regional recurrences in patients treated with $3 \mathrm{D}$ CRT and IMRT. Specifically, it is relevant to learn more about the cause of relapse, the dose delivered to the tissue in question and the proximity of the tumor 
recurrence to the original target structures. To address this issue, we have analyzed recurrence patterns in patients with recurrent $\mathrm{HNC}$ previously treated with 3D CRT and IMRT at our institution. A detailed mapping of the primary treatment, the patient dose distributions and subsequent recurrence patterns are provided.

\section{Methods}

\section{Patients}

We retrospectively reviewed the medical records of 112 patients with primary squamous cell carcinoma in the head and neck reirradiated between January 2007December 2013. To be included in the current study the following criteria had to be fulfilled: i) re-irradiation for first relapse in the head and neck region, ii) radiotherapy for both primary and recurrent disease at Oslo University Hospital, iii) Computed Tomography (CT), and/or Positron Emission Tomography (PET)/magnetic resonance images (MRI) taken prior to RT, iv) available RT dose plans for the primary and recurrent disease which were technically possible to co-register, v) completed their planned curative primary radiation treatment.

Of the 112 patients, 26 patients fulfilled the inclusion criteria. The general characteristics of the patients and tumor site are detailed in Table 1 . The patterns of recurrence were analyzed separately in 2 groups of patients

Table 1 Patients characteristics

\begin{tabular}{ll}
\hline & Number of patients \\
\hline Total & 26 \\
Median age & $65.5(42-86)$ \\
Sex & \\
Male & 20 \\
Female & 6 \\
Postoperative radiotherapy & 16 \\
Primary radiotherapy & 10 \\
Chemotherapy & \\
Yes & 2 \\
No & 24 \\
Tumor site & \\
Oral cavity & 13 \\
Parotid gland & 2 \\
Epipharynx & 4 \\
(Case No. 2, 22 and 24) & \\
Larynx & 12 \\
Tonsilla & \\
Nasal cavity & \\
Radiotherapy technique & 2 \\
IMRT & 14 \\
3D conformal & \\
\hline
\end{tabular}

based on the primary treatment they received; patients treated with primary RT $(n=10)$ and postoperative RT $(n=16)$. The time difference between primary RT and reirradiation varied between 4 and 63 months (Tables 2 and 3). At the time of recurrence, 16 of 26 patients had their gross tumor removed before reirradiation. In these patients, the gross tumor was delineated on the relapse RT CT images based on the diagnostic CT examination taken prior to relapse surgery.

Only 2 of the 26 patients received concomitant chemotherapy (Table 1). For the primary treatment, 12 of 26 patients received IMRT while 14 patients were treated with 3D CRT for their HNC disease as reported in Tables 2 and 3.

\section{Tumor delineation}

Tumor volumes were defined by an experienced radiation oncologist on simulation $\mathrm{CT}$ images acquired in conjunction with primary and recurrent $\mathrm{RT}$, registered in some cases with MRI and/or Fluorodeoxyglucose (18 F-FDG) PET images. The gross tumor volume (GTV; GTVp for primary GTV and GTVr for recurrence GTV) was defined as the visible tumor based on all available diagnostic imaging as well as clinical examination. The high risk and standard risk areas with $10 \mathrm{~mm}$ margin to GTV was included in the clinical target volume (CTV, CTVp and CTVr). CTV also included non-dissected lymph nodes. The planning target volume (PTV, PTVp and PTVr) was constructed by expanding the corresponding CTV by $3 \mathrm{~mm}[8,9]$.

\section{Image registration and overlap definition}

Relapse localization on CT images was further investigated by using the software module Oncentra Masterplan (version 4.3). The recurrence treatment planning $\mathrm{CT}$ for each included patient was exported to the respective primary dose plan-CT series. The exported recurrence dose plan CT was further rigidly registered with the primary dose plan-CT for each patient using available image registration tools. To achieve an optimal image registration, the information such as skull base, frontal bone and other bony structures were used. After CT image registration, the GTVr from the recurrence dose plan-CT was copied and pasted into the primary dose plan CT dataset. The HNC oncologist (JFE) also approved the quality of image registration for each included patient (Fig. 1).

To assess overlaps, the GTVr overlapping with the GTVp in each primary CT slice was identified and delineated as illustrated in Fig. 2. For cases with relapses located fully or partly in the elective nodes, no overlap volume was assessed. Then the dose of both the primary RT plan and of the reirradiation plan in the overlap area was calculated. 
Table 2 Primary treatment history - Patients treated with primary RT

\begin{tabular}{|c|c|c|c|c|c|}
\hline \multirow{2}{*}{$\begin{array}{l}\text { Case } \\
\mathrm{nr}\end{array}$} & \multirow{2}{*}{$\begin{array}{l}\text { Radiotherapy regimen } \\
\text { Fraction } \mathrm{D} \times \text { No of fractions }+/- \text { concomitant } \\
\text { boost (CB) or hyperfractionated RT (HF)/Total Dose }\end{array}$} & Radiotherapy technique & \multirow{2}{*}{$\begin{array}{l}\text { Treatment } \\
\text { year }\end{array}$} & \multirow{2}{*}{$\begin{array}{l}\text { Time difference } \\
\text { between first RT and } \\
\text { recurrence RT (In months) }\end{array}$} & \multirow[t]{2}{*}{ TNM } \\
\hline & & IMRT $=I$ and Conformal $=\mathrm{C}$ & & & \\
\hline 1 & 2 Gy $\times 23+$ CB 2 Gy $\times 12 / 70$ Gy & I & 2009 & 19 & T4N1M0 \\
\hline 2 & HF 1.5 Gy × $20+1.5$ Gy × 20/60 Gy & C & 2009 & 14 & T4N2bM0 \\
\hline 3 & 2 Gy $\times 23+$ CB 2 Gy $\times 12 / 70$ Gy & I & 2009 & 19 & $\mathrm{~T} 2 \mathrm{~N} 2 \mathrm{bM} 0$ \\
\hline 4 & 2 Gy $\times 23+$ CB 2 Gy × 12/70 Gy & C & 2008 & 41 & T4N2aM0 \\
\hline 5 & $1.5 \times 15+1.75 \times 4+1.5 \times 20 / 59.5 \mathrm{~Gy}$ & I & 2010 & 5 & T4N0M1 \\
\hline 6 & 2 Gy $\times 23+$ CB 2 Gy $\times 12 / 70$ Gy & C & 2009 & 63 & T2NOMO \\
\hline 7 & 2 Gy $\times 23+$ CB 2 Gy $\times 12 / 70$ Gy & C & 2008 & 22 & T3NOMO \\
\hline 8 & 2 Gy $\times 23+C B 2$ Gy $\times 11 / 68$ Gy & । & 2010 & 10 & T4aNxMO \\
\hline 9 & 2 Gy $\times 23+$ CB 2 Gy × 12/70 Gy & । & 2009 & 18 & T2NOMO \\
\hline 10 & 2 Gy $\times 23+C B 2$ Gy $\times 12 / 70$ Gy & । & 2009 & 10 & T3N2bM0 \\
\hline
\end{tabular}

To explain the cause of relapse, it was assessed whether the relapse occurred in the regional lymph nodes or not. The localization of the regional lymph node relapse was assessed by our oncologist.

The epicenter in GTVr and GTVp were defined, the dose and distance between the 2 epicenters were calculated. Epicenter was estimated from the center of mass. A mean epicenter distance value was calculated in cases with more than one GTVr.

The recurrence volumes were considered as in-field, marginal and out-of-field, if the dose in the epicenter of the recurrence volume was located in high, low or very low dose areas, respectively. Cases with their relapse located in 2 regional lymph nodes with different location, were labelled with 2 relapse site definitions but one mean epicenter dose.

\section{Statistics}

To assess the dose differences when employing IMRT or 3D CRT, a two-tailed independent $T$-test was employed. A $p$ value $<0.05$ was considered as statistically significant.

\section{Ethics}

All necessary approvals were obtained before the study was conducted. Written informed consent was obtained from all patients in accordance with the procedures of

Table 3 Primary treatment history - Patients treated with postoperative RT

\begin{tabular}{|c|c|c|c|c|c|}
\hline \multirow{2}{*}{$\begin{array}{l}\text { Case } \\
\mathrm{nr}\end{array}$} & \multirow{2}{*}{$\begin{array}{l}\text { Radiotherapy regimen } \\
\text { Fraction } D \times \text { No of fractions }+/- \text { concomitant } \\
\text { boost (CB) or hyperfractionated RT (HF)/Total Dose }\end{array}$} & \multirow{2}{*}{$\begin{array}{l}\text { Radiotherapy technique } \\
\text { IMRT = I and Conformal =C }\end{array}$} & \multirow{2}{*}{$\begin{array}{l}\text { Treatment } \\
\text { year }\end{array}$} & \multirow{2}{*}{$\begin{array}{l}\text { Time difference } \\
\text { between first RT and } \\
\text { recurrence RT (In months) }\end{array}$} & \multirow[t]{2}{*}{ TNM } \\
\hline & & & & & \\
\hline 11 & $2 \mathrm{~Gy} \times 23+\mathrm{CB} 2 \mathrm{~Gy} \times 2 / 50 \mathrm{~Gy}$ & C & 2010 & 33 & T1NOMO \\
\hline 12 & 2 Gy $\times 23+$ CB 2 Gy $\times 12 / 60$ Gy & C & 2007 & 43 & T4NOMO \\
\hline 13 & 2 Gy $\times 25 / 50$ Gy & C & 2011 & 6 & T1N0M0 \\
\hline 14 & 2 Gy $\times 23+$ CB 2 Gy × 10/66 Gy & I & 2011 & 35 & T2NOMO \\
\hline 15 & 2 Gy $\times 35 / 70$ Gy & C & 2010 & 10 & T1N0M0 \\
\hline 16 & $2 \mathrm{~Gy} \times 23+2 \mathrm{~Gy} \times 7+2 \mathrm{~Gy} \times 3 / 66 \mathrm{~Gy}$ & 1 & 2012 & 4 & $\mathrm{~T} 2 \mathrm{~N} 2 \mathrm{bM} 0$ \\
\hline 17 & 2 Gy $\times 23+2$ Gy $\times 7 / 60$ Gy & 1 & 2011 & 6 & $\mathrm{~T} 2 \mathrm{~N} 2 \mathrm{bM} 0$ \\
\hline 18 & 2 Gy $\times 23+2$ Gy $\times 7 / 60$ Gy & C & 2010 & 14 & $\mathrm{~T} 1 \mathrm{~N} 2 \mathrm{bM} 0$ \\
\hline 19 & 2 Gy $\times 23+$ CB 2 Gy $\times 7 / 60$ Gy & C & 2009 & 10 & T1N0M0 \\
\hline 20 & 2 Gy $\times 23+2$ Gy $\times 2 / 50$ Gy & C & 2012 & 6 & T1NOMO \\
\hline 21 & 2 Gy $\times 23+2$ Gy $\times 7 / 60$ Gy & C & 2010 & 7 & T2N1M0 \\
\hline 22 & 2 Gy × 33/66 Gy & । & 2009 & 35 & T4NOMO \\
\hline 23 & 2 Gy $\times 23+2$ Gy $\times 2 / 50$ Gy & 1 & 2013 & 9 & T2NOMO \\
\hline 24 & 2 Gy $\times 23+2$ Gy $\times 2 / 50$ Gy & I & 2006 & 59 & T3N2M0 \\
\hline 25 & 2 Gy $\times 23+2$ Gy $\times 7 / 60$ Gy & C & 2010 & 7 & $\mathrm{~T} 2 \mathrm{~N} 2 \mathrm{bMO}$ \\
\hline 26 & 2 Gy $\times 23+2$ Gy $\times 2 / 50$ Gy & C & 2010 & 5 & T2NOMO \\
\hline
\end{tabular}




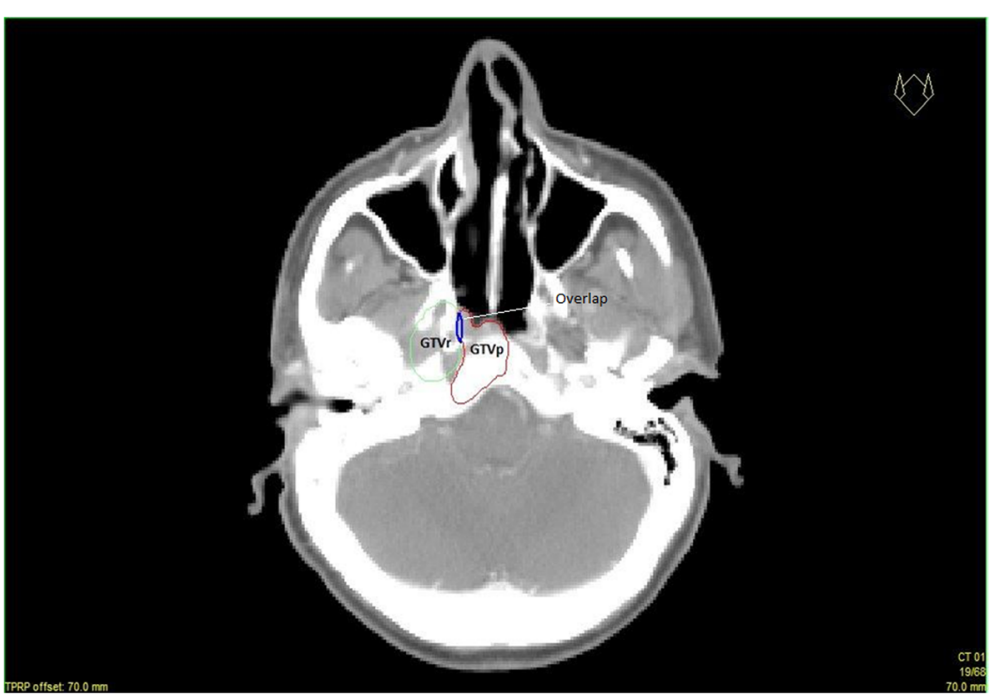

Fig. 1 Fusion display of primary (gray) and recurrence (pink) CT images

the Data Protection Office of whom also approved this study.

\section{Results}

The range of the total prescribed RT dose for primary HNC treatment was 50-70 Gy, as shown in Tables 2 and 3. In total $13(50 \%)$ of the failures occurred within 1 year after primary treatment, $6(23 \%)$ within 2 years and $7(27 \%)$ within 3 to 5 years. In patients treated with postoperative RT compared to those treated with primary RT, the fraction of the recurrences occurring within 1 year was approximately 3 times higher. The fraction of patients with relapse within 2 years was 4 times higher in the patient group treated with primary RT compared to postoperative RT patient group. The fraction of patients with relapse within 3-5 years after primary treatment was identical in both patient groups.

The population-averaged median dose to the recurrence volume for 26 patients receiving either IMRT or 3D CRT was 65.3, and 45.1 Gy, respectively (Data not shown). No statistically significant dose differences were observed between the employed RT techniques.

Recurrence occurred in the regional lymph nodes in 4 out of 10 patients treated with primary RT compared to

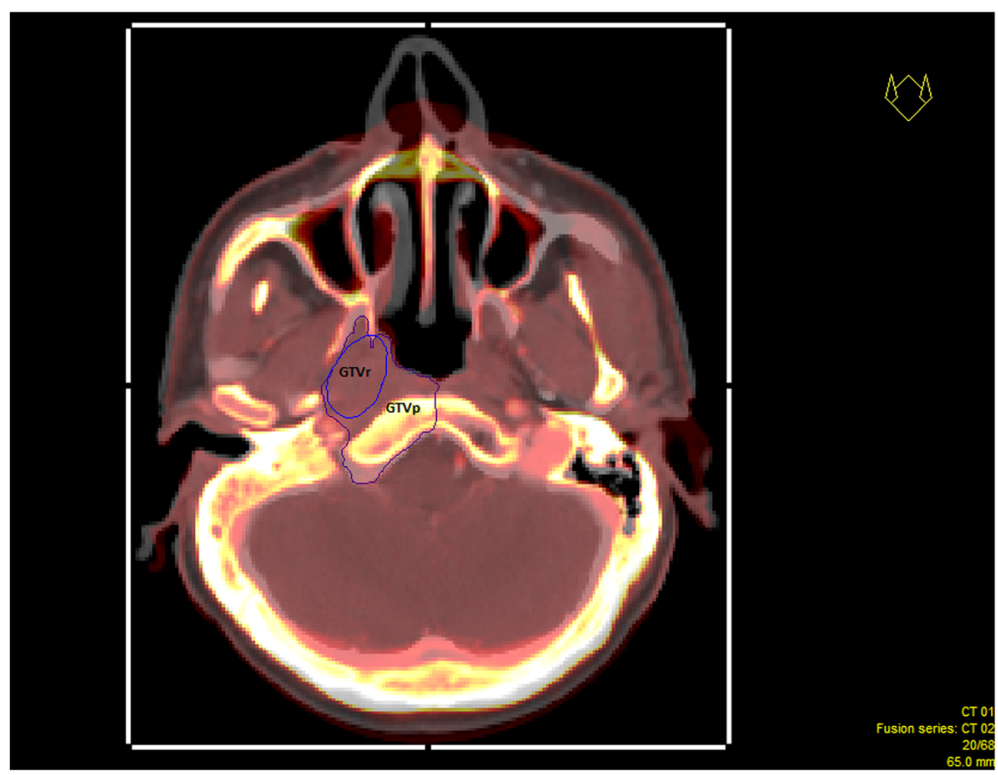

Fig. 2 Definition of overlap volume 
11 out of 16 patients treated with postoperative RT as shown in Tables 4 and 5.

Total relapse dose in patients who received primary RT varied from 27 to $71 \mathrm{~Gy}$ and in the patients treated with postoperative RT from 2 to 66 Gy (Tables 4 and 5). The dose in epicenters and distance between epicenters in GTVr and GTVp are shown in the Tables 4 and 5.

There were 1 and 3 out-of-field recurrences in patients treated with primary RT and postoperative RT, respectively. One of 10 patients treated with primary RT and 2 of 16 patients treated with postoperative RT had marginal relapses (Tables 6 and 7 and Fig. 3). Eight and 11 in-field recurrences were identified in patients treated with primary $\mathrm{RT}$ and postoperative $\mathrm{RT}$, respectively ( $\mathrm{Ta}$ bles 6 and 7 and Fig. 3). The GTVr and GTVp epicenter distance in patients treated with primary $\mathrm{RT}$ and postoperative RT was $0.4-6.1$ and $1.2-13.7 \mathrm{~cm}$, respectively. The average epicenter distance for in-field, marginal and out-of-field recurrences were $3.8,6.3$ and $9.4 \mathrm{~cm}$.

The size of recurrence volume varied between 6.5 to 76 $\mathrm{ccm}$ and 2.1 to $119.3 \mathrm{ccm}$ in patients treated with primary RT and postoperative RT, respectively (Tables 6 and 7).

The mean overlap size for primary RT was $10.4 \mathrm{ccm}$ $(\mathrm{SD} \pm 8.6)$ compared to patient group receiving postoperative $\mathrm{RT}$ of $5.6 \mathrm{ccm}(\mathrm{SD} \pm 11,8)$ (Tables 4 and 5 ) $(p=0.23)$.

Table 4 Site of relapse for patients with primary RT

\begin{tabular}{|c|c|c|c|}
\hline $\begin{array}{l}\text { Case } \\
\text { No. }\end{array}$ & Site of relapse & $\begin{array}{l}\text { Location of relapse } \\
\text { in lymph node } \\
\text { (yes =y or No }=N)\end{array}$ & $\begin{array}{l}\text { Total relapse } \\
\text { dose (Gy) as a } \\
\text { result of first RT }\end{array}$ \\
\hline 1 & $\begin{array}{l}\text { Partly inside the primary } \\
\text { tumor volume }\end{array}$ & $\mathrm{N}$ & 71.0 \\
\hline 2 & $\begin{array}{l}\text { Outside the primary tumor } \\
\text { volume and elective lymph } \\
\text { node volume }\end{array}$ & Y & 27.0 \\
\hline 3 & $\begin{array}{l}\text { Partly inside the primary } \\
\text { tumor volume }\end{array}$ & Y & 67.0 \\
\hline 4 & $\begin{array}{l}\text { Partly inside the primary } \\
\text { tumor volume and elective } \\
\text { lymph node volume }\end{array}$ & Y & 67.0 \\
\hline 5 & $\begin{array}{l}\text { Partly inside the primary } \\
\text { tumor volume }\end{array}$ & $\mathrm{N}$ & 43.0 \\
\hline 6 & $\begin{array}{l}\text { Fully inside the primary } \\
\text { tumor volume }\end{array}$ & $\mathrm{N}$ & 69.0 \\
\hline 7 & $\begin{array}{l}\text { Partly inside the elective } \\
\text { lymph node volume }\end{array}$ & Y & 50.0 \\
\hline 8 & $\begin{array}{l}\text { Fully inside the primary } \\
\text { tumor volume }\end{array}$ & $\mathrm{N}$ & 68.0 \\
\hline 9 & $\begin{array}{l}\text { Partly inside the elective } \\
\text { lymph node volume and } \\
\text { touches the primary tumor } \\
\text { volume }\end{array}$ & $\mathrm{N}$ & 64.0 \\
\hline 10 & $\begin{array}{l}\text { Partly inside the primary } \\
\text { tumor volume and elective } \\
\text { lymph node volume }\end{array}$ & N & 70.0 \\
\hline
\end{tabular}

\section{Discussion}

This study analyzed the failure patterns of $26 \mathrm{HNC}$ patients treated with RT for their relapse disease. Our analyses show that the majority of the failures occurred within 1 year after completed primary treatment. There was no statistical difference in the doses to the recurrence volume in patients treated with IMRT or 3D CRT technique. The majority of the recurrence in the patients treated with postoperative RT occurred in the regional lymph nodes. The recurrent lymph nodes were located fully or partly inside the elective lymph node region in the majority of these patients. The majority of recurrences were recognized as in-field, independent of the primary treatment.

Due et al. [10] have analyzed the recurrence pattern in 39 HN squamous cell carcinoma patients with locoregional failure treated with chemoradiation. Due and colleagues [10] reported that $96 \%$ of recurrences were located in the high dose region. Another study carried out by Soto et al. [11] showed that 100\% (9/9) of the included HNC patients with loco-regional failure were located inside the primary GTV. The shorter average epicenter distance of $3.8 \mathrm{~cm}$ between GTVr and GTVp, the high epicenter dose in GTVr and the reported site of recurrences in this study show that the majority of recurrences $(73 \%)$ are also located in high dose area in accordance with the studies of Due et al. and Sot et al. [10, 11].

In the study of Due et al. [10] all the included patients were treated with primary RT, while in the current study only 10 of the included patients received primary RT and 16 patients were treated with postoperative RT. Our results showed no correlation between the recurrence patterns and the kind of primary treatment the patients had received. The cause of relapse in the study of Due et al. [10] seems to be insufficient total dose to the primary GTV. However, in the present study the relapse could be due to: i) inadequate total dose to the primary target volume and/or ii) imprecise diagnostic imaging of the primary tumor volume leading to inadequate primary target delineation. In the majority of the cases (15/26) in our study, regional recurrences occurred in lymph nodes partly or fully located in the area of the primary GTV or elective lymph nodes. Therefore, it may be questioned whether the total dose in this area was adequate or not. In the marginal and out-of-field recurrences the cause of relapse seems to be due to the insufficient primary target delineation. Increased use of FDG-PET in defining the GTV as discussed in the study of Soto et al. [11] could probably improve the accuracy of the tumor definition.

IMRT and 3D CRT techniques are usually employed in the standard management of HNC patients. In only one of the marginal recurrences in this study IMRT technique was used in the delivery of their primary RT. 
Table $\mathbf{5}$ Site of relapse for patients treated with postoperative RT

\begin{tabular}{|c|c|c|c|}
\hline Case No. & Site of relapse & $\begin{array}{l}\text { Location of relapse in lymph node } \\
(\text { yes }=y \text { or } \mathrm{No}=\mathrm{N} \text { or partly }=\mathrm{P} \text { ) }\end{array}$ & $\begin{array}{l}\text { Total relapse dose (Gy) as } \\
\text { a result of first RT }\end{array}$ \\
\hline 11 & $\begin{array}{l}\text { Relapse in a lymph node partly inside the } \\
\text { elective lymph node volume and the other } \\
\text { lymph node outside the elective lymph } \\
\text { node volume and the primary tumor volume }\end{array}$ & Y & 44.0 and 45.0 \\
\hline 12 & Partly inside the primary tumor volume & $\mathrm{N}$ & 52.0 \\
\hline 13 & $\begin{array}{l}\text { Fully outside the primary tumor volume } \\
\text { and elective lymph node volume }\end{array}$ & Y & 15.0 \\
\hline 14 & Partly inside the elective lymph node volume & Y & 20.0 \\
\hline 15 & Fully inside the primary tumor volume & N & 66.0 \\
\hline 16 & $\begin{array}{l}\text { Partly inside the elective lymph node } \\
\text { volume and primary tumor volume }\end{array}$ & $\mathrm{N}$ & 60.0 \\
\hline 17 & $\begin{array}{l}\text { Relapse in one lymph node volume partly } \\
\text { inside the elective lymph node volume and } \\
\text { another lymph node fully inside the } \\
\text { elective lymph node volume }\end{array}$ & Y & 9.0 And 47.0 \\
\hline 18 & Fully inside the elective lymph node volume & Y & 59.0 \\
\hline 19 & Partly inside the elective lymph node volume & Y & 60.0 \\
\hline 20 & Fully inside the elective lymph node volume & Y & 38.0 \\
\hline 21 & Fully inside the elective lymph node volume & Y & 45.0 \\
\hline 22 & Partly inside the primary tumor volume & $\mathrm{N}$ & 66.0 \\
\hline 23 & $\begin{array}{l}\text { Outside the elective lymph node volume } \\
\text { and primary tumor volume }\end{array}$ & Y & 2.0 \\
\hline 24 & Partly inside the primary tumor volume & $\mathrm{N}$ & 50.0 \\
\hline 25 & $\begin{array}{l}\text { Outside the elective lymph node volume } \\
\text { and primary tumor volume }\end{array}$ & Y & 9.0 \\
\hline 26 & $\begin{array}{l}\text { Fully inside the elective lymph node } \\
\text { volume and also touches the primary tumor volume }\end{array}$ & Y & 41.0 \\
\hline
\end{tabular}

Increased risk of marginal misses is often mentioned as one of the disadvantages associated with IMRT [12]. Precise target definition is therefore crucial to avoid marginal miss.

One limitation of the current study is the heterogeneity of the patient cohort and their stage of disease. However, it is important to stress that the goal of this study was to assess the relapse localization and the cause of it. Another limitation is that the CT slice thickness in primary and recurrence CT scans were not always identical. This may have resulted in less precise fusion of the primary and relapse CT scans. In general, some uncertainty can be

Table 6 Patient treated with primary RT; recurrence volume size, recurrence site, overlap volume size, epicenter dose and distance between epicenter in GTVr and GTVp

\begin{tabular}{|c|c|c|c|c|c|c|}
\hline Case No. & Recurrence volume (ccm) & In-field & Marginal & Out-of- field & Overlap size $(\mathrm{ccm})$ & Epicenter dose (Gy) in GTVr/GTVp and distance (cm) \\
\hline 1 & 6.5 & $x$ & & & 4.0 & 71.4/70.2, 0.9 \\
\hline 2 & 17.4 & & & $x$ & 0.0 & $34.4 / 60.0,5.2$ \\
\hline 3 & 73.7 & $x$ & & & 17.1 & $69.2 / 71.2,3.7$ \\
\hline 4 & 44.3 & $x$ & & & 23.8 & 72.8/71.6, 1.7 \\
\hline 5 & 76.0 & $x$ & & & 18.3 & $56.2 / 61.5,1.8$ \\
\hline 6 & 74.7 & $x$ & & & 15.8 & $71.5 / 71.6,0.4$ \\
\hline 7 & 41.1 & & $x$ & & 0.0 & $54.7 / 72.4,4.5$ \\
\hline 8 & 15.6 & $x$ & & & 15.0 & $67.8 / 66.7,3.0$ \\
\hline 9 & 46.4 & $x$ & & & 7.3 & $70.5 / 71.2,4.2$ \\
\hline 10 & 14.2 & $x$ & & & 7.3 & $70.2 / 68.8,2.8$ \\
\hline
\end{tabular}


Table 7 Patient treated with postoperative RT; recurrence volume size, recurrence site and overlap volume size, epicenter dose and distance between epicenter in GTVr and GTVp

\begin{tabular}{|c|c|c|c|c|c|c|}
\hline Case No. & Recurrence volume (ccm) & In-field & Marginal & Out-of- field & Overlap size (ccm) & Epicenter dose (Gy) and distance $(\mathrm{cm})$ \\
\hline 11 & 88.9 & $x$ & & & $0.0 / 0.0$ & $44 / 49.2,6.6$ \\
\hline 12 & 24.2 & & $x$ & & 1.5 & $48.8 / 61.5,5.5$ \\
\hline 13 & 76.6 & & & $x$ & 0.0 & $0.7 / 50.8,12.0$ \\
\hline 14 & 18.0 & $x$ & & & 0.0 & $66.4 / 65.2,2.8$ \\
\hline 15 & 5.8 & $x$ & & & 2.6 & $65.5 / 69.0,2.9$ \\
\hline 16 & 86.6 & $x$ & & & 37.7 & $64.3 / 61.7,4.9$ \\
\hline 17 & 20.1 & & $x$ & & $0.0 / 0.0$ & $44.0 / 59.9,8.8$ \\
\hline 18 & 5.2 & $x$ & & & 0.0 & $63.0 / 58.6,4.9$ \\
\hline 19 & 2.1 & $x$ & & & 0.0 & $62.9 / 62.7,5.2$ \\
\hline 20 & 18.2 & $x$ & & & 0.0 & $45.3 / 50.4,9.2$ \\
\hline 21 & 59.5 & $x$ & & & 32.6 & $45.8 / 57.8,9.3$ \\
\hline 22 & 13.5 & $x$ & & & 9.5 & $65.2 / 69.7,1.2$ \\
\hline 23 & 119.3 & & & $x$ & 0.0 & $1.6 / 49.8,13.7$ \\
\hline 24 & 27.2 & $x$ & & & 4.3 & $52.7 / 52.7,2.8$ \\
\hline 25 & 59.0 & & & $x$ & 0.0 & 6.9/59.6, 6.7 \\
\hline 26 & 27.1 & $x$ & & & 1.3 & 46.4/49.7, 4.1 \\
\hline
\end{tabular}

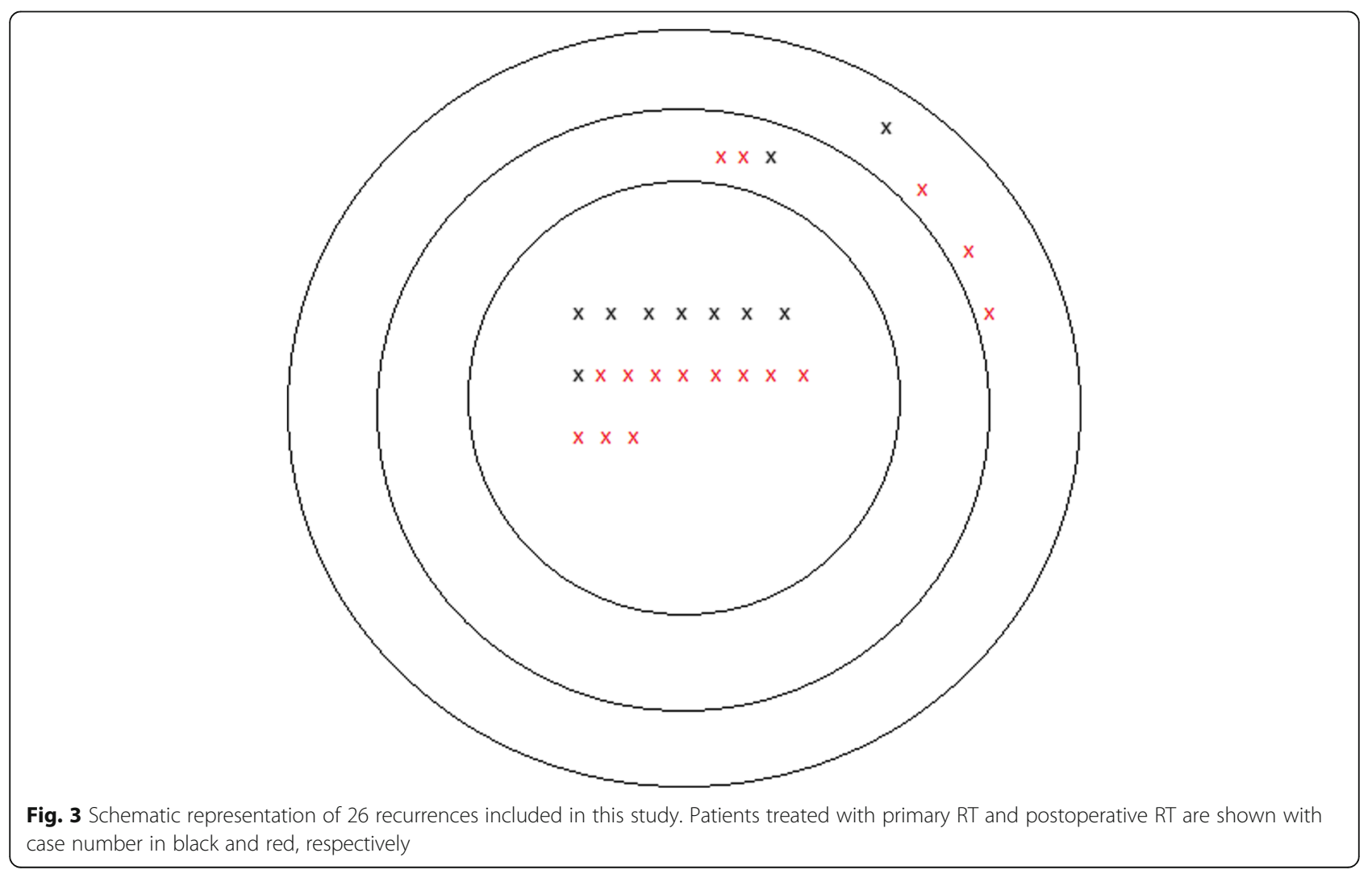


associated with the rigid registration process because of anatomical changes between the primary and recurrence RT. However, our experienced oncologist has studied the detailed disease information in each medical record and diagnostic CT images and compared them with the recurrence localization assessed after registration. Another limitation when using rigid registration is inaccurate estimate of the dose distribution in the $\mathrm{CT}$ series of the recurrence volume.

\section{Conclusion}

The cause of recurrence in the majority of the patients seems to be inadequate dose to the primary treatment volume and in some few cases due to imprecise primary diagnostic imaging leading to inadequate primary target delineation. The majority of recurrences were recognized as in-field, independent of the primary treatment. Further investigation is necessary to evaluate the total RT dose needed to treat the primary HNC. Optimal diagnostic methods should be employed to avoid poor primary target delineation.

\section{Abbreviations \\ 18 F-FDG: Fluorodeoxyglucose; 3D CRT: Three-dimensional conformal radiotherapy; CT: Computer tomography; CTV: Clinical target volume; GTV: Gross tumor volume; HNC: Head and neck cancer; IMRT: Intensity- modulated radiotherapy; MRI: Magnetic resonance images; PET: Positron emission tomography; RT: Radiotherapy}

\section{Acknowledgements}

This study was supported by a grant from the Norwegian Cancer Society.

\section{Funding}

None

\section{Availability of data and materials}

Contact the corresponding author

\section{Authors' contributions}

SJ carried out data collection, study design and drafted the manuscript. JFE contributed to data quality assurance. EM, ED and CDA contributed to study design, participated in the drafting of the manuscript and review. MHN contributed to the data collection. TF contributed to establish the employed rigid fusion method and contributed to the drafting of the manuscript. All authors read and approved the final manuscript.

\section{Competing interests}

The authors declare that they have no competing interests.

\section{Consent for publication}

Obtained

Ethics approval and consent to participate

Obtained

\section{Publisher's Note}

Springer Nature remains neutral with regard to jurisdictional claims in published maps and institutional affiliations.

\section{Author details}

${ }^{1}$ Department of oncology, Division of cancer Medicine, Surgery and Transplantation (KKT), Oslo University Hospital-Radium hospital, Montebello, 0310 Oslo, Norway. ${ }^{2}$ Oslo and Akershus University College of Applied Sciences, Faculty of Health Sciences, Oslo, Norway. ${ }^{3}$ Department of Physics, University of Oslo, Oslo, Norway. ${ }^{4}$ Department of Medical Physics, Oslo University Hospital, Oslo, Norway.
Received: 27 February 2017 Accepted: 19 May 2017

Published online: 25 May 2017

\section{References}

1. Braakhuis BJM, Leemans CR, Visser O. Incidence and survival trends of head and neck squamous cell carcinoma in the Netherlands between 1989 and 2011. Oral Oncol. 2014;50(7):670-5.

2. Cancer in Norway 2010, Cancer Registry of Norway, Institute for epidemiological cancer research.

3. Kam MK, Chau RM, Suen J, et al. Intensity-modulated radiotherapy in nasopharyngeal carcinoma: Dosimetric advantage over conventional plans and feasibility of dose escalation. Int J Radiat Biol Phys. 2003;56:145-57.

4. Xia P, Fu KK, Wong GW, et al. Comparison of treatment plans involving intensity-modulated radiotherapy for nasopharyngeal carcinoma. Int J Radiat Oncol Biol Phys. 2000:48:329-37.

5. Chao KS, Deasy J, Markman J, Haynie J, Perez CA, Purdy JA, et al. A prospective study of salivary function sparing in patients with head-andneck cancers receiving intensity modulated or three-dimensional radiation therapy: initial results. Int J Radiat Oncol Biol Phys. 2001;49:907-16.

6. Eisburch A, Marsh LH, Martel MK, Ship JA, Ten Haken R, Pu AT, et al. Comprehensive irradiation of head and neck cancer using conformal multisegmental fields: assessment of target coverage and noninvolved tissue sparing. Int J Radiat Oncol Biol Phys. 1998;41:559-68.

7. Jeong S, Yoo EJ, Kim JY, Han CW, Kim KJ, Kay CS. Re-irradiation of unresectable recurrent head and neck cancer: using Helical Tomotherapy as image-guided intensity-modulated radiotherapy. Radiat Oncol J. 2013;31(4):206-15.

8. Ng WT, Lee MC, Hung WM, et al. Clinical outcomes and patterns of failure after intensity-modulated radiotherapy for nasopharyngeal carcinoma. Int J Radiat Oncol Biol Phys. 2011;79:420-8.

9. Dawson LA, Yoshimi A, Marsh $L$, et al. Patterns of local-regional recurrence following parotid-sparing conformal and segmental intensity-modulated radiotherapy for head and neck cancer. Int J Radiat Oncol Biol Phys. 2000;46:1117-26.

10. Due AK, Vogelius IR, Aznar MC, et al. Recurrences after intensity modulated radiotherapy for head and neck squamous cell carcinoma more likely to originate from regions with high baseline [18 F]-FDG uptake. Radiot Oncol J. 2014;111:360-5.

11. Soto SE, Kessøer ML, Piert M, et al. Correlation between pretreatment FDGPET biological target volume and anatomical location of failure after radiation therapy for head and neck cancers. Radiot Oncol J. 2008;89:13-8.

12. Mendenhall WM, Amdur RJ, Palta JR. Intensity-modulated radiotherapy in the standard management of head and neck cancer: promises and pitfalls. J Clin Oncol. 2006:24(17):2618-23.

Submit your next manuscript to BioMed Central and we will help you at every step:

- We accept pre-submission inquiries

- Our selector tool helps you to find the most relevant journal

- We provide round the clock customer support

- Convenient online submission

- Thorough peer review

- Inclusion in PubMed and all major indexing services

- Maximum visibility for your research 